\title{
Coping with Young Delinquents in Naples: an Approach in Clinical Sociology (between Foucault and Marcuse)
}

\author{
Massimo Corsale*
}

Suor Orsola Benincasa University, Naples, Italy

\begin{abstract}
Young delinquents in Italy are seldom convicted in jail: in the most cases they stay within little communities (less than ten guests) where social workers give them some educational opportunities. The paper is concerned with some experiences made with such boys, aiming to put them in a situation where they could try a different relation with rules: they usually come indeed from a social marginal environment, where rules (namely the ones accepted in central society and enforced by law) are generally refused; here two experiences are examined: a regular job within a big manufactory (electrical household appliances), as well as a practical sailing course with participation to a big final regatta, where the boys have had a positive relation with rules, namely the ones necessary to achieve the goals connected with the experience. From a theoretical point of view, such experiences could give a new perspective on the classical concept of "discipline" proposed by Foucault, putting it in relation with the Marcuse's theory of "necessary/additional repression".
\end{abstract}

Keywords: Clinical Sociology, Social Marginality, Cultural Patterns, Discipline, Rules.

\section{A THEORETICAL PREMISE}

What's the task of sociology face to human suffering? Does sociology (so as other sciences) have some role in helping people to overcome their suffering?

According to common sense, the answer should be obvious: yes, of course, science in general and sociology specifically can (and must) help people in this concern.

Usually common sense doesn't fully satisfy our sophisticated conceptual needs, but anyway it often gives us a first push to look for better answering our questions. For laymen indeed, science must at last be useful for people, for their everyday life: otherwise why should we make so many efforts (and invest so much money) to develop our knowledge? This is quite evident for all sciences aiding us to overcome nature and to take advantage of technology. Something like this could also be said about normative sciences, so as medicine, psychology or educational science: these ones indeed have by definition the purpose of helping people some way (though sociologists could often raise some problems about such a way, and in my opinion they should: and this could be one of the tasks of clinical sociology).

For better or not, sociologists couldn't take any advantage of resources like those of other scholars. All along the era of industrial society they shared, or better

*Address correspondence to this author at the Suor Orsola Benincasa University, Naples, Italy; Tel: +39-329-4123735

E-mail: massimocorsale@yahoo.it they underlined the common opinion concerning the progressive destiny of Western society, according to the idea of progress proposed by philosophers coming from Enlightenment and Positivism. For them too indeed the actual social system would overcome its problems and contradictions, either by automatic mechanisms (functionalism) or by revolutionary transformations (Marxism). So sociologists should only favour such new balance by analyzing problems and contradictions and proposing their best solutions to policy makers, either reformist or revolutionary. The tradition of social problems study, as well as that of the Chicagoan school in the USA, so as that coming from Durkheim in Europe, have all been involved in the reformist perspective, while the Frankfurt school was more oriented to a revolutionary, or at least to a radical one.

The coming of a post-industrial society has upset all the games on the table. It could be observed from different points of view: technological, economic or others; but from a sociological one the most important change has been that industrial working class has lost its central role in promoting a progressive change aiming to socialism. Consequently the idea of socialism itself, either as a more balanced society, or as a radically new one without market, is over. The default of class struggles in UK under Mrs. Thatcher's government during the last Eighties, as well as the refusal from the part of a new leftist party, born in Italy at the beginning of present century, to be named "socialist" (though most of its members were coming from the communist party), these are, among others, meaningful symptoms of such a situation. 
May be too many leftist people (collective movements as well as individuals) are today paradoxically yearning for the past, namely for that industrial society where roles in the drama of class struggle were well established, and forecasting an eschatological future was allowed. But, though its dramatic consequences on everyday life of people, the so-called (and so blamed) new liberalism could also be considered the present form of the typical attitude of capitalism to create by destroying, so as Schumpeter (but Sombart and Nietzsche before him) still pointed out (Reinert H. and Reinert E.S. 2006). Neither national political organizations, nor the trade unions movement, and even less sociologists could bias such a global trend with realistic successful chances. Maybe postindustrial society should be better named post-modern because of its giving up of the typical modern Promethean attitude: that's supposing men able to govern nature and society as well, and drive them according to their own purposes.

Sharing all the above analysis of the present situation would involve, in my opinion, to acknowledge a key role for a clinical approach in sociology. Sociology indeed is generally interested in social problems, that's in phenomena giving some trouble to people in society coming from specific relationships with other social phenomena (Touraine 1974). A clinical approach in sociology namely involves focusing a problem concerning a specific community or even a single person, aiming to help them to get off from such troubling situation. Nevertheless this kind of practice anyway carries on indirect contributions to general theories, namely by promoting a more critical attitude towards their latent premises.

In such a perspective, I would like to submit some experiences with young delinquents, made in Italy and particularly in the region of Naples, that I think to be interesting examples of a clinical approach coherent with the specific outlines of contemporary society.

\section{SOME NOTES ABOUT MARGINALITY AND DEVIANCE IN THE NAPLES AREA}

Most young delinquents in the Naples area come from marginal contexts, placed both within downtown and in poor suburbs of the city ${ }^{1}$.

\footnotetext{
${ }^{1}$ Naples together its hinterland is an about 4 million inhabitants city, in Southern Italy. It lies on the Mediterranean seaside, within a very beautiful natural environment (near Sorrento, Capri, Ischia, Pompei) and it enjoys an important historical and artistic inheritance. But nowadays it is affected by heavy economic and social problems, as well as by a widespread criminality.
}

Marginality as a sociological concept was very much discussed some decades ago, when it was used to implement theories of social inequality and class struggle, as well as of modernization and economic development. Within my discourse indeed, "marginality" would only describe a specific situation, a social status where people (individuals as well as social groups) are pretty far from the "centre" of the social sub-system they refer to: that's far from the milieus where dominant styles of life and cultural patterns are worked out, and where there is as well the possibility of influencing decisions concerning the whole system. Then marginality involves specific attitudes towards social institutions, while these ones, within marginal contexts, carry on different functions than usual in modern societies.

Marginal families generally enjoy a low income, often below the poverty level, that leads them to implement it both by subsidies coming from community administrations and by illegal jobs. Illegality, in such cases, may be either from the part of employers (who often don't pay social security and health contributions for such workers), or from the part of workers, who for instance make a little trade without licence, or sell products carrying false trademarks, or smuggled cigarettes or even drugs (both light and hard); by this way it's not difficult to reach micro-delinquency, or even the big organized criminal business. Of course, we have to keep in mind that there is no automatic mechanism carrying people to become an offender, but marginal people are all influenced by cultural patterns where boundaries between legal and illegal behaviours are not well marked.

Such families live usually in old or even crumbling houses, or in more recent ones but early damaged because of a bad building style as well as of an unsuitable use from the part of inhabitants: generally indeed they are overcrowded with promiscuity. Parenthood and its roles are wrenched, not only compared with those usually considered normal by psychologists, but also with the so-called "napoletanità": i.e. a set of cultural patterns deeply rooted in the popular tradition of that area, where, for instance, mothers had a great influence in softening violent habits of their sons. Nowadays on the contrary they tend to enforce, by their children, cultural patterns rather cynically oriented to consumption and waste. Fathers, on their side, are usually absent: they are in jail, or laying in addiction to drugs or alcohol, or at last they are going around to catch money some way. In any case they have no relevant influence on rearing 
their children, as they rather tend to leave apart the traditionally protective role of fathers by choosing regression towards animal male roles (so as it happens everywhere, indeed, in the slums). Young people in their turn, both boys and girls, contempt behaving patterns proposed by the prevailing culture and by its institutions (school, mass-media etc.), as they prefer to look at the only winning ones (in their opinion): those of the organized gangs of that area, the so-called "camorra".

As for the school, teachers run painfully after their pupils, though rather weakly believing in their capability to really influence such situation. They are doubtful, moreover, about the way to arrange contents and behaving patterns pertaining to the institutional culture together with those of marginality. And, what's more, it's not evident to them the very way to consider marginality: whether as a really different culture earning to be respected and to establish relations with; or rather as a criminal sub-culture in the same sense as it was proposed by Sutherland (1939) at his time. The first perspective, on the contrary, has been the one chosen by a teacher working with a strong involvement within one of the most difficult areas in the region, and describing her experience by a very interesting book (Melazzini 2011)

Among the contents of such sub-culture we can meet also deep-rooted habits of a casual distribution of time between day and night, as well as of eating hours and of what to eat, so carrying out a really casual diet. The same could be said about choosing friends and partners, as well as about allocating free time, all the more so because boundaries between free and job time are really fleeting. Not to speak about the relations with money. But anyway they don't risk to die for hunger: they only suffer precariousness, uncertainty, disorder, lack of dignity (when, for instance, they catch or even require with arrogance a public subsidy) and after all they are accustomed to trespass the boundaries between legal and illegal behaviour. And from such trespassing often comes to them a relevant income.

It should be evident, indeed, that marginality doesn't mean automatically professional delinquency. It means, on the contrary, that often within the same familial clan are living side by side fellows seeking to keep legal behaviour (though being not well convinced about a real rationality of the established legal order), and other ones that, for the same reason, at last fall in the very deviance: drugs or alcohol addiction, brave behaviour with motorbikes and cars, bad and aggressive boasting behaviour, thefts and robberies, etc. Within such a social environment, we can find also young fellows too early recruited by big criminal organizations: sometimes they come from a familial clan already joining in one of such organizations, but more often they join in because these ones can give young brave people a more fashionable living perspective.

As a matter of fact these culturally underprivileged people, and mainly young people, often don't suffer a so heavy real, material poverty, but to be sure they suffer a cultural one: their cultural horizon is so narrow, that they don't look at any other purpose, in their life, than benefits consisting of material everyday things (wears, motorbikes, etc.) able to put them above their mates in a competition where the prize is the favour of the most glamorous girls in the quarter. And for our boys achieving such a goal could often be possible only by committing crimes: thefts, violent robberies, drug trading etc.

Their behavior seems to be motivated by all three fundamental needs pointed out by McClelland (1961): achievement, power, affiliation. They would like to be "the best" within their juvenile marginal milieu, in order to have authority therein and to gain the best consideration from the part of the feminine public at hand. By this way making it also evident that achievement pattern works quite everywhere, also within underdeveloped social areas; while it isn't enough to promote, by its own, social and cultural development (so as McClelland had suggested).

\section{COPING WITH JUVENILE DELINQUENTS IN THE AREA: A ROLE FOR THE FACTORY CULTURE}

Actual Italian institutions checking juvenile delinquency have a twofold penitentiary organization: on the one side there are jails (generally one for each region, two in the region of Naples), where the most heavy cases are treated; on the other side, there is a lot of little communities, each one holding less than ten people (mainly boys, but sometimes also girls) in a house, managed by some social workers as a private, no-profit organization. Communities promote schooling, working, making sports for their guests, but also teaching them rules of a good behavior in a private as well as in a public milieu.

The Associazione Jonathan is just an organization managing some of such communities in the Naples area. It is strongly engaged in promoting human 
empowerment of their guests by projects aiming to broaden their cultural horizon: new experiences, to be carried out within social and cultural contexts previously unknown to them, but where they could learn to look at rules and social norms not only as limiting their free behavior, but also as something empowering their capacity to achieve their own goals.

In this regard I would like to speak about a project Jonathan is carrying on since several years in a close relation with one of the biggest manufacturing corporations in Italy, the Merloni group (electrical household appliances): a project that more recently has been spread to include other big corporations such as FIAT (motors and cars) and Barilla ("pasta" and cookies). These corporations have agreed with Jonathan to employ some boys coming from the communities by drawing up regular time-contracts with each one of them. We have to remember, indeed, that our boys usually remain in the community only for a short period; and that, on the other hand, nowadays the most of new entries among industrial workers in Italy are employed with time-contracts (while on the contrary senior workers enjoy a strong protection against dismissal). Anyway, during this period (usually, six months) the boys go everyday to work, side by side with the other industrial workers, following the same working times, enforcing the same rules, and receiving a regular salary.

In this concern we have to keep in our mind that since several decades working outside the jail is considered, in Italy, an important element of the usual strategy for socialization and reinstatement of prisoners, so enforcing the constitutional rule that imprisonment should become an occasion for social rescue of offenders. And in such perspective not only working is important, but furthermore to work in a normal working environment, outside the jail, is far more important.

But actually in the overall most cases (so as I have personally verified during my experience as a social worker inside juvenile jails in the past years), such a touch with the real labour world takes place outside the normal labour market, mainly within little handicraft firms, furthermore within firms which are paid by penitentiary administration for their service. Which advantage could young prisoners receive from such an experience (for instance, by working in a "pizza" or in a tyre shop) beyond a little salary?

First of all, working in such conditions doesn't let the person to perceive the right meaning of labour, its dignity as well as that of the very person doing it: independently on how much it could be paid, how worthy at last may socially be a labour performance for which someone (different from the worker) has to be paid for making it possible? We have to remember, indeed, that for the first time in the Wester history, capitalism and the protestant culture assigned to labour (manual and intellectual as well) a dignity correspondent to its market worth, whilst within traditional cultures, before capitalism, working was considered something slavish, or the consequence of a biblical judgement. And it is not casual that in Neapolitan culture (influenced by traditional patterns), labour is still named "fatica", that means hardship.

That's why Jonathan-Merloni project plays a so basic role within the educational strategy of Jonathan. The reason is paradoxically that it plays an important role also within the managerial strategy of Merloni Corp. (as well as of the other Corporations there included). Also leaving apart the image reward coming to them from such a transaction, we have to consider that they are buying on the labour market, according to the law, labour performances that will be paid at the right price, just because they need them in order to accomplish their productive function and to earn the right profit. In other words, here we have the same kind of social relations as those described by Adam Smith when he spoke about his meal, owed not to the liberality but to the profit of the butcher, of the baker and the brewer as well. By this way the boys working according to the project perceive the social importance of their performance, and the social dignity of their own. So they can escape their usual degrading option between social aid and delinquency.

Furthermore the project is bearing some important outcomes from another point of view. We have already spoken about the disorder, the lack of rules characterizing the everyday life of our marginal boys. Well, working within a factory makes a radical turning up in their life-style: it compels them to strictly conform to the time-tables for getting in and out, to the established working times, to the hierarchical relations. In other words, we are speaking about the capacity of factory system to discipline fellows.

I would like to pay a special attention to the concept of discipline, that raised so much problems among social scientists. Maybe the very source of such problems lays in Weber's definition of discipline (Weber 1920), where obedience without questions to a commander entitled by a formal power was central. 
And where a strong scent of Prussian military tradition is evident. So as evident too is the Foucault's reference to such definition, when he puts the problem of discipline at the centre of his historical and sociological research on total institutions (asylums, jails, hospitals etc.). And everyone knows very well the political (revolutionary) suggestions intrinsic to Foucault's writings (Foucault 1972, 1975).

But I have to note that nowadays we need a much more complex concept or discipline. We could consider it as the capacity of internalizing ethical and social rules in force within the culture shared by the subject. Everyone could observe immediately the consonance of such definition with the Parsons' one of socialization: that's not casual, because Parsons' main problem was the Hobbesian one, that of order in society (Giddens 1976); and nobody could deny the close relations existing between order and discipline. Weber however pointed out formal legitimation of commanding power to be very important, but without considering the reasons why subordinated people would be induced to obey. Maybe for a German sociologist it was easy to take for granted a widespread trend to enforce the rules from the part of subject people. To me, on the contrary, as a sociologist coming from Naples, such trend is not obvious at all. Our everyday experience shows that a rule needs something further than a legitimated power to be enforced: it needs motivations internal to the subject in order to enforce it or not.

The first motivation, to be sure, is convenience: but that of avoiding punishment (that's the Hobbesian one) is not enough, so as everyday experience in the marginal areas of Naples region shows. People could indeed consider some perspectives connected with infringement preferable than to avoid the risk of punishment. That depends on the importance given by marginal people to cultural patterns different from the ones shared by central population.

But generally speaking, convenience could also be found, from an universalistic point of view (and here Parsons could support us again), by following cultural patterns which inspire law. As a matter of fact, in their everyday life usually people don't obey single rules, but rather follow the cultural patterns staying behind law: people (so as even myself) usually don't know the most of rules in force in their country, while cultural patterns, on the contrary, are internalized by single subjects during their socialization process.

Before modernization of Western world, a socialization according with the global Western
Christian culture in force at that time was easy, because of the rigid structures of that societies, where single persons could very hardly choose behaviours inconsistent to their status. Modernization, on the contrary, made life chances ever more open to everyone: peasants were no longer bound to land, they could go to the towns, even go to the New World, where they could become entrepreneurs. Rigid structures of feudal societies no longer guided individual lives, so that it became necessary to establish more compelling institutions for socialization, to promote a strong internalization of patterns shared in the global culture. By this way people could finally guide themselves by their own in their everyday life in society, having missed the external guide formerly established for them by the Middle Age societal structures.

Among such institutions for socialization, beside school, jail, asylum, college and military camp, there is the modern industrial factory too, with its internal rules, with its "basic assumptions" (so as Edgar Schein named them: 1985), with its machinery conditioning the most of such rules. Some Italian scholars (such as Melossi and Pavarini, 1977) compared industrial factory with jail, the both considered to be repressing institutions: to be sure such a statement is based on a widespread interpretation of Marx's theory of alienation bound to the role of machinery. In my opinion, on the contrary, for the working class it is much better to be bound by labour schedules influenced by machineries within capitalistic factories, than by those deriving from the whip of inspectors or of galley-sergeants, as it happened before.

But the most important difference between factory and the majority of other repressive institutions is that by working in a factory one can realize how rules are important in order to achieve one's own ends (namely the ones of the whole organization, that indeed are the same, in a community perspective). This is actually a fundamental, decisive difference, because rules in such perspective are no longer sheer instruments of repression.

Factory system indeed does rule not only labour timing, but also the free time. After one day's work, with the related physical and psychological stress, people need above all to recover their energies, to "reproduce the labour-force" (according to the Marx's speech). Then, living times so as eating, sleeping etc. have to satisfy such recovering needs; so entertainment too has to be according to them and not contradictory. It's 
evident, at last, that for a marginal boy factory system represents the "other half of the sky", that's just that normal-central world formerly looking unreachable to him. That's why the ongoing experience coming from the Jonathan-Merloni project seems to enjoy an increasing agreement from the part of the young boys there involved.

Someone, I think, could make some reasonable remarks concerning such Jonathan way to deal with marginality and juvenile delinquency: namely that of inconsistency of socializing people to cultural patterns of factory system, at the same time when everywhere people speak about a post-industrial society characterizing our new century. Someone as an Italian industrial sociologist, for example, has named "labour century" the XXth one, referring to the fact that the ours would be not characterized anymore by a decisive role of factory labour (Accornero 2000).

Without involving us in a so complicated discussion, only indirectly connected with our theme, it would make sense to point out that a post-industrial society will need some kind of rationality in ruling everyday behaviours as well as labour ones, exactly in the same way as the industrial society. And that to be sure such a rationality would be quite different from that actually "ruling" (so to speak) everyday life in marginal areas. Finally, anyway, it would be an important educational step forward, for young people growing up within such areas, to experience so different cultural perspectives and behavioural patterns than their usual. To know different cultures lets people consider their own from outside, so enabling them to take a critical attitude to it. In other words, it carries out a real empowerment of our teen-agers.

\section{SAILING AS AN EXPERIENCE PROMOTING HUMAN EMPOWERMENT}

A sailing school is another way essayed by Associazione Jonathan for promoting human empowerment of the boys restrained within its communities.

Actually sailing might be considered as a metaphor of life, while a boat could help our moral growing up by compelling people to face unforeseeable difficulties. Moreover when people share such experience with other partners, they become a crew with mutual expectations to be satisfied, and so the experience comes to a more radical level.

Satisfying mutual expectations implies that everybody keeps his(her) own place and plays his(her) own role: that means to set up a well disciplined group. Discipline however can be pursued at first by a repressive way, that's only by threatening punishment. This is the authoritarian look of discipline, the way that Hobbes was thinking about, but also the one mainly analyzed by Foucault $(1972,1975)$, from whom indeed comes the very bad opinion about it, a largely shared one. A good example of such a way could be found within ancient galleys, where rowers were generally prisoners compelled to bear their biggest strain by the threaten of a whip. By the way, we should observe that such a kind of discipline hasn't any good relationship with educational strategies, because people obeying only under threaten of punishment are likely to no longer obey when such a threaten will stop: that's the case of what Granovetter has named "ypo-socialized people" (Granovetter, 1985).

Disciplining strategies however aren't to be restricted to the authoritarian ones only: pedagogists, for example, often speak about non-authoritarian methods. From a socio-clinical point of view however, we have to refer first of all to a phenomenological analysis of the socialization process.

People, both in their early childhood and in their adult age, build their view of the world, of their own life world (Schutz 1932) basing it on experiences. Experiences are interpreted, that's are given sense by the actor, and sense is the specific meaning assumed by the event experienced when it is considered within its specific context (Corsale 2010). Events have indeed a generic meaning within a culture (with its common sense and its current language), a meaning depending on the institutions, in other words on the social practices ongoing within such culture. But each event happens in a specific situation, in a context, where it can be given a specific meaning, properly a sense, and such context involves not only exterior circumstances, but also the very life stream of the actor. So, as the life stream consists of a series of experiences, every new experience becomes a new part of such life stream. There are, on the one side, people interested to make new experiences and then to implement their living world, to enlarge their horizon; while on the other side there are people not interested in it. But new experiences actually pose some problems to the both.

An experience arrives when an event becomes conscious, and then it is positively or negatively judged for the life of the actor: when events are relevant for the actor, then they are charged with value (whatever value do we refer to, in the case), and by this way they 
influence his(her) foreseeable future. As a matter of fact indeed, our behavior is always future oriented, but our view of the future depends on our preceding life stream: so each new experience can confirm our preexisting view of the "world of life", but it could also disconfirm it. In such last case we have to change our view, that could imply some disease to the actor. That's the reason why actors very often make efforts to bring back every new experience within their pre-existing view of the world.

The only way for inducing them to pay attention to new experiences involving a change is to show the new positive opportunities there connected: once more we have to do with convenience (in other terms, with satisfaction of needs), which supports actors in making the effort for implementing their world, for enlarging their horizon.

The impact with rules is one of the most significant experience for an actor, because rules seem to introduce limits to his(her) free choice. Rules indeed are met by actors since their early childhood, and always raise the same negative reaction, at first. Anyway when one realizes their effectiveness, then he(she) cannot disregard them anymore, because taking them into account could only permit to by-pass their bad consequences. There is not a single way, however, for taking into account rules, but rather two at least.

Once realized the effectiveness of a rule, the actor can feel confirmed, at first, about its limiting capacity, without any other positive consequence for the actor him(her)self. In this case, independently on the fact that such feeling is right or wrong, the actor could simply submit to the rule because he(she) thinks not to be able to escape it. On the contrary, he(she) could choice to infringe it, as he(she) thinks to be able to escape its bad consequences. In such case the decision depends on the actor's opinion about his(her) own strength face to the threatening power of the rule. Little kids are generally unconscious about their real strength, and then they often face serious risks. Boys coming from marginal environments indeed often like to challenge rules coming from the global social system, and prefer to submit to the ones coming from their own (deviant) sub-culture. In such cases, repeating and underlining threatens of punishment would be rather ineffective to them.

But an actor could also become aware that a rule can be useful for enabling him(her) to pursue some interesting aims. In such case he(she) might be ready not only to take into account, but rather to internalize such rule, so making it a new spring of his(her) future behavior (Corsale 2010). When that arrives, behavior of the actor may be considered really disciplined (according to rules), because it's evident that such a discipline fits much deeper within the conscience of our actor.

That's difficult, in this case, is rather to help the actor to become aware of the usefulness of the rule. And this is just the aim of Jonathan's project about sailing training. Sailing indeed implies first of all to live some time very close to other mates on a boat, and therefore it involves a strong regulation of such a life in common. Secondly, it implies learning techniques and rules for driving the boat; but mainly it involves internalizing a new idea of rules and norms in general (a new one for boys coming from a marginal deviant milieu). The new idea is that rules and norms are not only troubling limits to their free behavior, but also and mainly necessary ways for achieving their own goals. On the boat the goals concern first of all a safe sailing, and then a good placement in the regatta at the end of the training course. So as in everyday life, rules and norms are ways for achieving goals, and by this way (the pleasant experience of sailing) internalizing discipline could become more effective, without needing a violent repression.

\section{RULES, SOCIALIZATION AND DISCIPLINE. THE ROLE OF CLINICAL SOCIOLOGY}

Maybe someone would ask whether the problems concerning disciplining strategies, such as we have spoken about until now, have some relationships with clinical sociology, or not. Anyway my answer is: yes, they have, and moreover they could help us to better understand the specific role clinical sociology should play within the system of sciences and its relationships with everyday life. Let's explain how this could be.

Young delinquents we are concerned with are suffering a punishment, and since long ago there is a general agreement about the idea of detention as an educational opportunity for delinquents, much more if they are boys or girls. This idea is grounded upon the assumption that delinquents lack "education", by which term we generally mean an institutionalized process of socialization to the culture of the actual general social system. In the terms of Parsons, delinquents would lack "values" shared by the most members of society: taking for granted that a good socialization process implies internalization of the whole set of such values. 
By the way, with reference to this I would prefer speaking about "cultural patterns", instead of "values" so as Parsons does. The term "value" indeed does properly mean a sheer criterion of judgement, that could be used either in a positive or in a negative sense: for example, something can be judged either beautiful or not (aesthetic value), as well as good or not (moral value). To say that someone shares a criterion is a quite generic assertion, while people do share better a concrete use of such criterion to qualify something determined: for example, when we say "this thing is good, while this other one isn't". In such cases however we have an evaluation, an assertion that something can be positively or negatively evaluated referring to a specific value (ethic, aesthetic, legal or other). When assertions like these are shared on a large scale within a social context, I think it's better to name them "cultural patterns", because they finally play two fundamental roles: that of giving a shared meaning to specific items of the life world of members, but at the same time that of ruling attitudes for facing them. Actually indeed one could also say that rules are meanings of behavioral patterns, while at the same time meanings are rules for using such patterns. Then, the name of "cultural patterns" seems to be fit to underline their role of connecting a culture with social regulation of standard behaviors.

Anyway, socialization does at last consist of learning such rules, such cultural patterns. Then the actor about whom Hobbes had spoken can rightly be considered "ypo-socialized", so as Granovetter (1985) proposed, because of his (her) lack of cultural patterns learning, and then his(her) lack of socialization. While on the other hand the Parsonsian actor could be considered "yper-socialized", as he(she) has to internalize the whole set of cultural patterns shared in the social context.

The both ideas, however, seem to have not hit the mark, to have failed a fit analysis of the real socialization process. Actually indeed, this one goes on (so as we all know very well) since the beginning of the actor's life, being carried out by members of the nearest social context of the actor. These ones teach him(her) current language (that's the rules of using each word or expression of that language), but at the same time they teach the right attitude to take, facing the behaving pattern meant by each word. In other terms, they teach the cultural patterns shared within their larger context.

Kids do learn all this very quickly, but that doesn't mean that they really share it. As an instinctive reaction they at first reject all they think as limiting their possibility of satisfying their needs. But quickly they realize that to go against those rules may involve some negative reactions from the part of adult members of their context. Then they have an option: either to submit to adults' authority and by this way to be free of bad consequences from their part (but also to be limited in satisfying their wishes), or to infringe, so facing the risk of punishment. The decision between such alternative options is quite opportunistic: at first the kid is a Hobbesian individual (in spite of all the fanciful theories concerning natural moral sentiments of the humans, and notwithstanding Adam Smith's reasonable but not decisive considerations about sympathy: Smith, 1759).

Nevertheless they later do realize that some of those rules could help them to achieve their own aims: rules indeed provide people with all kinds of means enabling them to obtain some outcomes they possibly wish. Rules at last pertain to institutions, which are social practices suggesting to people a standard way for satisfying some of their needs by a system of standard meanings shared in their context. When kids realize that opportunity, then they are ready to internalize those rules (cultural patterns) which they see useful for their aims. Since that moment such rules can also work as spurs to act, and not as limits any longer.

Such a process goes on all along the life, as far as the socialization process is a lifelong one. And by this way we can bypass the Hobbesian ypo-socialized individual as well as the Parsonsian yper-socialized one. Actually each individual is building all along his(her) life a personal culture, a sort of personalized dictionary by which he(she) can give a standard meaning, or better a personalized sense to all that happens there around. But finally personal cultures of the members of a social context give place to a shared collective culture as far as people succeed when they essay to communicate to each other by using their personal "dictionaries".

Our young delinquents too have their own dictionary. They don't lack cultural patterns, anyway: they have internalized a set of the ones shared within their marginal social context. Such patterns are not always inconsistent to the ones regulating the general social system (otherwise the most members of such contexts should be delinquents), but sometimes they are, and moreover there is no right hierarchy regulating mutual relationships. But one of the most widespread 
patterns, particularly in marginal areas of Naples region, is a general distrust about rules coming from an authority, and often a real defiance to them.

Which strategy could we then carry out, to effectively discipline our marginal boys? The experiences of Associazione Jonathan suggest a convergence of two ways. First of all, it consists of proposing to our boys an experience quite different from their usual ones, an experience getting them within an horizon much larger than their own. From this new point of view, they are enabled to look at their usual native one from outside, that's the first condition for taking a critical attitude face to one's own culture. By this way indeed people (and then our boys too) can realize that their native culture doesn't provide the unique point of view over the world. There are also other points of view, that make the world much more complex, but also much more understandable. Working within a modern factory on the ground of a regular job relation, on the one hand, as well as living a training experience to sail and to take part in a regatta, to be sure can be seen as ways enabling our boys to take a distance from their native culture.

Such a change of perspective is necessary for putting our subjects in a problematic situation, but it is not enough to enable them to catch a new perspective over their life. A new perspective indeed might be a realistic, but also an unrealizable one. The latter would be actually something dragging them out of their right way, therefore it would be very negative from an educational point of view. On the contrary, it would be positive to show them two important things at the same time. The one is that difficulties and risks are not only connected with living in a marginal underprivileged milieu, but with living anywhere, also with a quite different horizon of life. For example, one of the boys engaged in the sailing training observed, during an interview, that sailing, though amusing, is however very heavy too. But the second thing our boys can catch and keep in their mind is that rules are not only something unbearable as limiting their chances of living, as anyway there are many rules providing the right means for making realizable what they are aiming to.

And we still know that this is the very condition which makes it possible to internalize rules and cultural patterns. But which rules and patterns? The whole set of them, so as Parsons suggested, or better only a selected set of them? Anyway the question is important also because it implies revisiting the role of a socioclinical approach.
People do not internalize as much cultural patterns as they learn. We still know that they take note of their existence in order to make an utilitarian choice between different options there connected. Up to this point indeed we remain within a Hobbesian perspective, involving that a disciplined behavior depends solely on the repressive capacity of authorities managing power.

But as a matter of fact such a kind of relationships between power (at every level) and subjects can only realize a precarious social order. We should remember that Montesquieu still considered the fear (of repression) as the basic principle only of Asian despotism, while Western monarchies and republics would be based on more involving principles, so as loyalty and political virtue.

But one could observe indeed that in those systems based on fear too do work some cultural patterns helping authority to achieve its tasks (while without them it couldn't work). I'm referring to religious patterns, which within all pre-modern or early modern authoritarian political systems plaid a decisive role to limit power of the leaders. In other words, religious patterns, on the one side, strengthen the leaders' commands by redoubling the source of fear: the threat of being punished both by the leaders and by God. But on the other side they limit the power of leaders by the fear (once more!) of a punishment by God: an impious leader indeed misses legitimacy. At this concern we could also quote an ancient Persian emperor, Ardashir I (III century b.C.) who said: "The altar and the throne have to support each other reciprocally, because a king without faith is a tyrant".

By this argument one would mean that disciplined collective behavior needs in any case internalization of a set of cultural patterns, from the part of the individuals. But in a given social context, such a set of cultural patterns must be shared by both the central and the marginal members. Then speaking about our delinquent boys, what's important from an educational point of view is that such a set should become consistent to that where the global social system is grounded.

The Marcuse's distinction between necessary and additional repression (Marcuse 1955) would help us very much in this case. Of course, the whole set of rules and cultural patterns regulating global society is generally perceived as unbearable by our boys. But we have to help them to distinguish on the one side rules 
necessary to collective survival, as well as the ones useful to permit the achievement of individual important goals, from rules and patterns to be considered, on the other side, uselessly repressive. And then we have to help them to internalize the former, and to refuse the latter ones. Rules and patterns functional to be fit to a working factory, as well as to a sailing boat, to be sure pertain to necessary repression, and then they are to be internalized (as far as we consider factory system and sailing to be relevant and useful institutions yet in our society: that could be another interesting topic for a clinical sociologist, nowadays).

To quote Marcuse, and particularly his Eros and Civilization (1955), within our context is actually neither casual, nor irrelevant. Marcuse was one of the most influent members of the Frankfurt school in philosophy and sociology, which established a cultural and political tradition that many clinical sociologists are still referring to nowadays, more or less explicitly. Marcuse however, as well as the Frankfurter founders Horkheimer and Adorno, were completely plunged in the dominant question of their time: that of the option between an alienating capitalistic system and a (presumably) liberating socialism.

To refer again to such masters today (after their strong revival during the Sixties and the Seventies of last century) would be actually inconsistent, in my opinion, as we are living in a totally different society. But the quest for a critical role, from the part of present clinical sociologists, could be satisfied by referring to that particular contribution by Marcuse, which in my opinion yet saves its fresh taste now.

Then, coming back to the question I posed at the beginning of our discourse, we are able to answer in what sense sociology, and especially clinical sociology, could help people to overcome their suffering.

Delinquency indeed gives rise to social suffering: to be sure, among people who are victims, but also among delinquents themselves. As a matter of fact these latter can never live a quiet life, as they are conscious of being always on the boundaries of at least two sets of conflicting cultural patterns.

An effective educational strategy carried out by a team of social workers including clinical sociologists would be likely to reduce such suffering, on the both sides. Indirectly among victims, as far as it could make a change in the young delinquents' lifestyle. But (that's much more important) on the side of these latter, first of all by opening a way of real communication between boys and social workers, where the former can feel to be taken into a real consideration, and then to be strengthened in their identity (Barus-Michel, GiustDesprairies and Ridel 1996). In the second place, by making experiences radically new, such as the ones above described, they can try to look at their own prior cultural patterns from outside, as an object to be evaluated and criticized.

I think however that the role of a clinical sociologist should not be limited to reduce social suffering within a specific social context (so as, for example, it would be the group of young delinquents managed by Associazione Jonathan). Clinical sociology indeed, when applied in some specific situation should anyway pose general problems concerning social dynamics, as well as it should aim to understand (in a Weberian sense) social phenomena there connected.

In this perspective, a clinical sociologist deeply involved in a daily dialogue with our boys could also be induced to look at his (her) own cultural patterns from outside, in the same way as the boys themselves. At last, to be bended on suffering people (so as the term "clinic" etymologically means) can involve an enrichment of the scientific horizon.

On the both sides indeed (the one of the boys as well as that of the clinical sociologist), such enrichment could come from a comparison between the reciprocal cultural patterns, that would clear possible contradictions both within the boys' ones and in the sociologist's, as well as give rise to problems with some trends working in the general process of social change. At this point they all have to choice either, what and how to change in their point of view, and the boys aren't any longer in the classical lower position as to institutional workers. By the way, one could underline the difference between such an equalitarian attitude of the clinical sociologist, and the medical one usually assumed by psycho-therapists.

A clinical approach in sociology however should not mean, in my opinion, pursuing generic social criticisms grounded on some ideological theory, whatever it would be. Speeches like these couldn't help anyone to reduce suffering, while on the other hand they are politically ineffective. The above approach, on the contrary, should mean that a specific social practice, carried out to face some problem of suffering, doesn't come from a common sense knowledge of laymen, but it could be better put in relationship with sociological 
theories able to understand micro as well as macro phenomena. In other words, the specific item would be put in a quite scientific perspective. In our case the liaison between theories by Marcuse and Foucault and the educational experiences of the boys could be considered a good example of such a micro-macro interaction.

\section{REFERENCES}

Accornero A. (2000): Era il secolo del lavoro. Bologna, II Mulino.

Anderson N. (1923): The Hobo. University of Chicago Press.

Barus-Michel J., Giust-Desprairies F., Ridel L. (1996): Crises. Approche psychosociale clinique. Paris, Desclées de Brouwer.

Corsale M. (2010): L'attore sociale e la principessa Turandot. Torino, L'Harmattan.

Foucault M. (1972): Histoire de la folie à l'âge classique. Paris, Gallimard.

Foucault M. (1975): Surveiller et punir. Paris, Gallimard.

Giddens A. (1976): The New Rules of Sociological Method: a Positive Critique of Interpretative Sociologies. London, Hutchinson.

Granovetter M. (1985): "Economic Action and Social Structure: the Problem of Embeddedness", in American Journal of Sociology, 91, 481-510.

http://dx.doi.org/10.1086/228311

Gutting G. (1989): Michel Foucault's Archaeology of Scientific Reason. Cambrudge University Press. http://dx.doi.org/10.1017/CBO9781139172141

Hannerz U. (1980): Exploring the City. Colombia University Press.
Hobsbawm E.J. (1985): Bandits. London, Penguin Books.

Hoy D.C. (ed.) (1986): Foucault: a Critical Reader. Oxford, Blackwell.

Hunt A., Wickham G. (1994): Foucault and Law. Toward a Sociology of Law as Governance. London, Pluto.

Marcuse H. (1955): Eros and Civilization. A Philosophical Inquiry into Freud. Boston, Beacon Press.

McClelland D.C. (1961): The Achieving Society. Harvard University Press.

Melazzini C. (2011): Insegnare al principe di Danimarca. Palermo, Selleria.

Melossi D., Pavarini M. (1977): Carcere e fabbrica. Bologna, II Mulino, 1977.

O'Farrel C. (2002): Foucault: the Legacy. Queensland University of Tehnology Press.

Reinert H., Reinert E.S. (2006): The Destructive Creation in Economics: Nietsche, Sombart, Schumpeter. Berlin, Springer.

Schein E. (1985): Organizational Culture and Leadership. New York, Jossey Bass.

Schmitt J.C. (2006): "L'histoire des marginaux ». In Le Goff J. (ed.): La nouvelle histoire. Paris, Complexe.

Schutz A. (1932): Der sinnhafte Aufbau der sozialen Welt. Wien, Springer. http://dx.doi.org/10.1007/978-3-7091-3108-4

Smith A. (1759): The Theory of Moral Sentiments. Now in Glasgow Edition of the Works and the Correspondence of A.S., I, Oxford, Clarendon Press, 1976.

Sutherland E.H. (1939): Principles of Criminology. University of Chicago Press.

Weber M. (1920): Wirtschaft und Gesellschaft. Tübingen, Mohr.

\section{DOI: http://dx.doi.org/10.6000/1929-4409.2013.02.43}

(C) 2013 Massimo Corsale; Licensee Lifescience Global.

This is an open access article licensed under the terms of the Creative Commons Attribution Non-Commercial License (http://creativecommons.org/licenses/by-nc/3.0/) which permits unrestricted, non-commercial use, distribution and reproduction in any medium, provided the work is properly cited. 